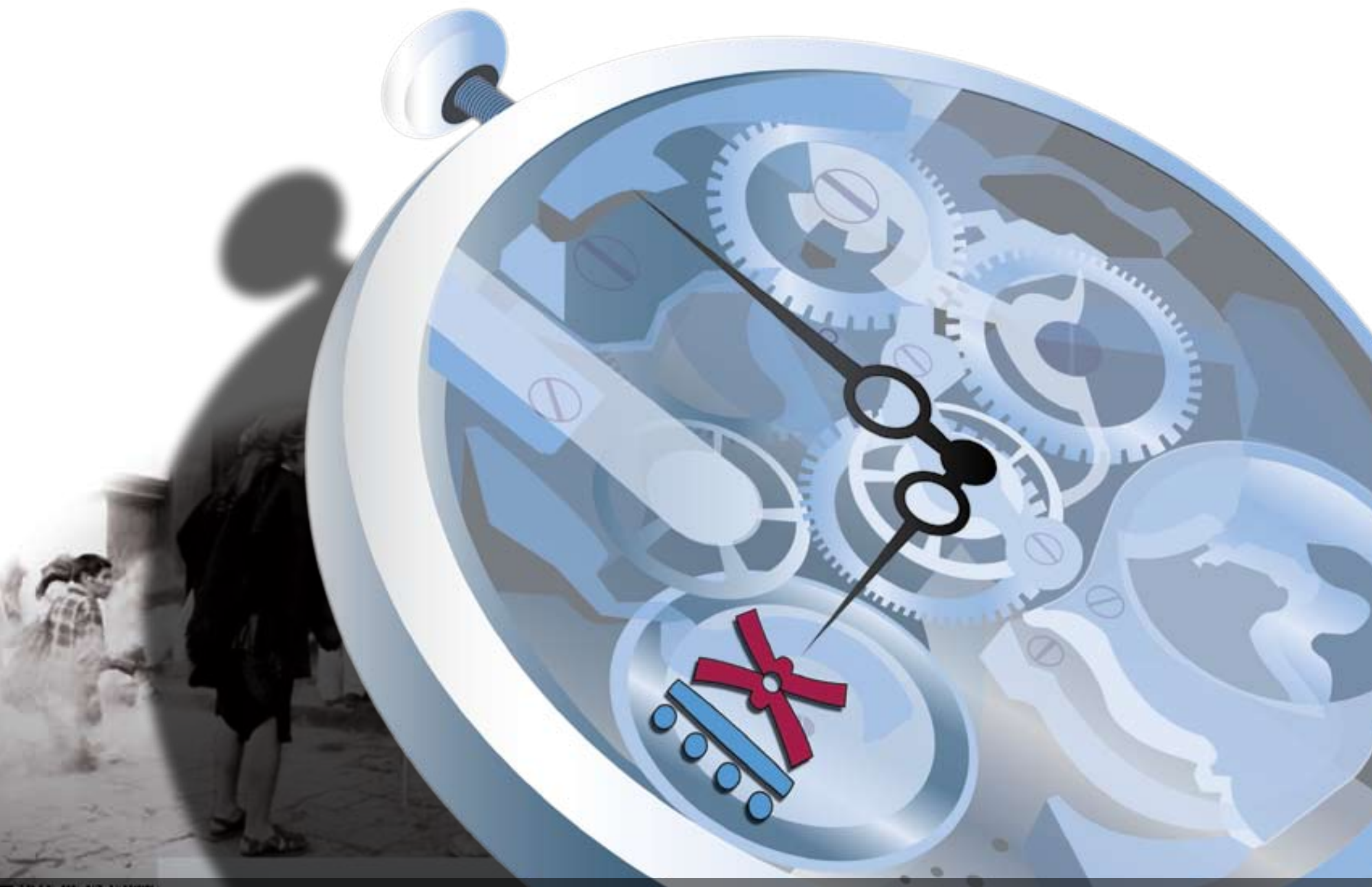

$9^{\circ}$ C O N G R ES O 2. CENTROAMERICANO DE H IS TO R I A
Universidad de Costa Rica

ISSN 1409-469X

Fecha de recepción: 15 de mayo 2008 Fecha de aceptación: 30 de mayo 2008

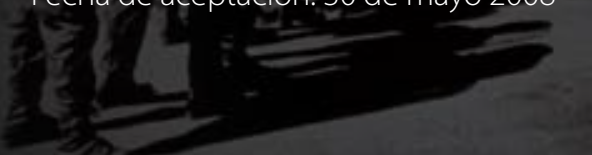

LAS DEVOCIONES A LA VIRGEN DE LA BALA Y SAN

LÁZARO COMO PRECURSORAS DE LA ATENCIÓN DE LA LEPRA EN LA CIUDAD DE MÉXICO

Miembros del Consejo Editorial:

Dr. Ronny Viales, Dr. Juan José Marín

Editores Técnicos:

Allan Fonseca, Andrés Cruz, Gabriela Soto

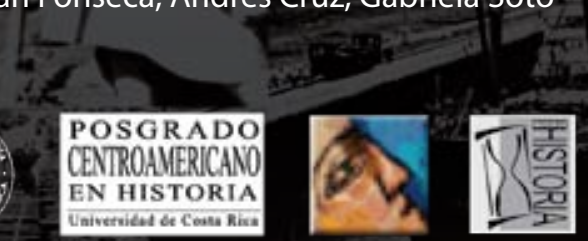




\section{LAS DEVOCIONES A LA VIRGEN DE LA BALA Y SAN LÁZARO COMO PRECURSORAS DE LA ATENCIÓN DE LA LEPRA EN LA CIUDAD DE MÉXICO}

Lic. Nain Alejandro Ruiz Jaramillo, Calle Pino

\# 51, Col. El Manto Iztapalapa, CP. 09830, tel:

26362050, itzamnain@hotmail.com. Actualmente estudio la maestría en historia del arte en el Instituto de Investigaciones Estéticas de la UNAM. 


\section{Consideraciones sobre la lepra en la época prehispánica}

Aparentemente la lepra es una enfermedad que fue traída y transmitida a América por los europeos en el siglo XVI; sin embargo, la polémica en torno a la existencia de este padecimiento en la época prehispánica sigue vigente. Probablemente la controversia la inició el patólogo Virchow en octubre de 1873, justo en la primer Conferencia Internacional de Lepra llevada a cabo en Berlín. En ella el patólogo mostró su teoría por medio del estudio que practicó en cráneos peruanos. También señaló le existencia de pictografías y vasijas antropomorfas moche donde aparecen imágenes de individuos y personajes que sugieren el padecimiento de esta enfermedad. ${ }^{1}$ Ashamed, Chico, Orvañanos y Flores fueron médicos que simpatizaron con esta tendencia. ${ }^{2}$ Tales observaciones aún hoy son fuente para argumentar dicha hipótesis. Los registros más sugerentes en México son varias esculturas antropomorfas de la Costa de Nayarit que muestran heridas y representaciones patológicas similares a las de la lepra. ${ }^{3}$

La prueba más contundente parece estar en Perú, país que se sigue perfilando como el único lugar de la América prehispánica con probable presencia de la endemia, pues se han realizado pruebas de $\mathrm{ADN}$ a restos óseos de una momia, a la cual se le identificó rasgos de este padecimiento; ${ }^{4}$ sin embargo, dichos resultados tienden a ser confusos por la limitada evidencia ósea y esta clase de pruebas pudieran ser de otro tipo de enfermedad.

Por otra parte hay registros historiográficos que aparentemente ratifican la existencia del mal, pues diversas fuentes hablan sobre la lepra. Hasta en la obra de Fray Bernardino de Sahagún, Historia General de las cosas de la Nueva España se dan recetas de cómo los mexicas la trataban..$^{5}$ En otros textos se designa la existencia de bubas y llagas entre los malestares que

1 José Terencio de las Aguas, Consideraciones histórico-epidemiológicas de la lepra en América, Med. Cutan Iber. Lat. Am, 2006, p. 179.

2 Algunas personas no profesionales al tratar de mostrar pruebas fehacientes dicen que hay pictografías en vasijas, relieves y estelas mayas que supuestamente muestran indicios de la enfermedad, sin embargo, la mayoría de quienes afirman esto, no dan las referencias exactas ni los fundamentos en los que se basan. Esta tendencia se advierte sobre todo en páginas de Internet.

3 Dominique D. Verut. M. D., Precolombina dermatology \& Cosmetology in Mexico, Italy, Amilcare Pizzi, 1973, pp. 20, 21, 22, 25, 41.

4 A. Rafl, M. Spigelman, J. Stanford, E. Lemma, H. Donoghue y J. Zias, "DNA of Mycobacterium leprae Detected by PCR in Ancient Bone" en International Journal or osteoarchaelogy, Estados Unidos. North American Editor, Associate Editors, 1994, pp. 288-290.

$5 \quad$ En el número 57 del apartado De las enfermedades y medicinas contrarias dice lo siguiente: “A los 
padecían los indígenas. ${ }^{6}$ Otra evidencia también se circunscribe en el aspecto religioso, pues investigadoras como Doris Hayden ${ }^{7}$ y Johana Broda, entre otros más, afirman que Atlantonan era la diosa patrona de los leprosos y que Tláloc y sus Tlaloques eran quienes causaban esta enfermedad a los hombres. ${ }^{8}$

Nuevamente los anteriores datos no corroboran que se esté especificando la enfermedad aquí estudiada. ${ }^{9}$ Además cuando los indígenas se referían a que Atlantonan era la patrona de quienes padecían llagas y bubas no significa que sea estrictamente lepra, recordemos que a lo largo de la historia muchas enfermedades fueron confundidas con el mal de San Lázaro. Igualmente, el que se hayan registrado características de la enfermedad en algunas esculturas de

que tienen la enfermedad de la lepra les suele acaecer pelárseles la ceja, y tener gran hambre, y para curarla será necesario tomar los baños dos o tres veces, y saliendo de los baños será también bueno untarse con hierbas y raíces de suso nombradas, molidas y beber el agua de cierta raíz que se llama tecpatli, y cuando no aprovecharen estos remedios apartarlos de la conversación de la otra gente porque no se les pegue., Fray Bernardino de Sahagún, Historia General de las cosas de Nueva España, anotaciones y apéndices de Ángel María Garibay K., México, Porrúa, 1997, pp. 592, 593. Los remedios son similares a los referidos en la Biblia, recordemos que esta obra fue escrita muchos años después de la Conquista y por indios adoctrinados.

6 El dios llamado Nanahuatzin, cuyo sacrificio implicó el nacimiento de nuestro astro solar, tenía el cuerpo cubierto por bubas y llagas.

7 Doris Hayden, "El cuerpo del dios: el maíz", en Animales y plantas en Mesoamérica, Coordinadora Yólotl González Torres, CONACULTA, INAH, México, Sociedad Mexicana para el Estudio de las Religiones, 2001, pp. 27-28.

8 Al respecto Johana Broda comenta lo siguiente: Además de ser los dueños de la lluvia y de los montes, los Tlaloques eran los patronos de ciertas enfermedades de la piel como la lepra, las bubas y las sarnas; también lo eran de la hidropesía y mandaban «las enfermedades causadas por el frío» como la gota, el tullimiento, el envaramiento del pescuezo, etc. todos los que morían de estas enfermedades, tenían el privilegio de ir al Tlalocan. Se reconoce fácilmente la relación causal que se había establecido entre las enfermedades y los Tlaloques: entre «las enfermedades causadas por el frío» y las montañas donde hace más frío que en el Valle [...] en cuanto a la lepra, las bubas y las sarnas, la gente creía que el agua cura estas enfermedades. Durán menciona que en la fiesta de Tepeihuitl la gente se bañaba en los ríos y las fuentes. Creía que si no se lavaban contraerían enfermedades contagiosas «como eran bubas, lepra... de los cuales males decían que sucedían por los pecados que estos dioses se los enviaban en venganza de ellos» Johana Broda, "Las fiestas aztecas de los dioses de la lluvia: una reconstrucción según las fuentes del siglo XVI", en Revista de Antropología Española Americana, Madrid, Vol. 6, [s.n.], 1971, pp. 255. 256. En este aspecto la diosa Atlantonan no deja de ser una deidad desconcertante porque era abogada de quienes padecían de llagas abiertas, y bubas, incluso se creía que ella era quien originaba los dolores y síntomas de estos padecimientos. De igual forma era patrona de los nacidos con deformidades físicas, entonces tales padecimientos por su carácter mítico, a pesar de ser repugnantes y despreciados en la actualidad, adquirían connotaciones de "enfermedad divina" en la época prehispánica. También otros dioses causaban la lepra entre los hombres, tales como Titlahuan, y Xipe entre otros relacionados con la piel.

9 Esta misma diosa tenía relación con el maíz y el mal que padece esta gramínea, llamado huitlacoche, que en este contexto hipotético, de alguna manera simbolizaba la $\square$ lepra $\square$ del maiz. La masa de este producto agrícola, en otros pueblos prehispánicos como el maya, era fuertemente vinculada con la creación del hombre y la carne humana. Actualmente el hongo es consumido para deleite del paladar mexicano. 
Nayarit y en personajes como Nanahuatzin puede deberse a múltiples factores sintomatológicos de diversas patologías de la piel. ${ }^{10}$

El tema de la lepra en la época prehispánica no deja de ser polémico y apasionante puesto que no hay certeza sobre si en realidad hubo algún tipo de esta enfermedad, ya que en la actualidad sabemos que existen diferentes géneros de lepra. ¿Habrá existido una variación menos maligna o virulenta en Mesoamérica? Hasta la fecha no se sabe, pero es de hacer notar que el doctor Rafael Lucio encontró una manifestación en particular que solamente se padece en México y era desconocida en el mundo hasta el siglo XIX. Bien pues, aquí continúa abierto el tema para que en futuras investigaciones multidisciplinarias se despeje la incógnita. En todo caso lo más importante, como dice la investigadora Ana Paulina Malavassi Aguilar "no es saber la fecha y el lugar exacto de la aparición de una enfermedad, sino el momento en el cual la sociedad toma conciencia de las implicaciones políticas, sociales y económicas (también de prevención, profilácticas y de salubridad agregaría yo) que conlleva la misma”. ${ }^{11}$

\section{La lepra en la época novohispana}

Cuando la lepra se manifestó innegablemente durante el proceso de Conquista, dominio y poblamiento hispano del territorio amerindio, nunca fue una preocupación primordial de las autoridades virreinales, quizá porque la advertían poco riesgosa para la población indígena de América, a pesar de que la patología es de consideración y necesita de medidas preventivas para evitar su transmisión. Probablemente no se le dio la importancia porque su forma de contagio es relativamente mínima y causaba un bajo impacto de mortalidad, por lo que no puso en peligro la vida de grandes sectores de la población como en su momento lo hicieron la viruela o el sarampión. ${ }^{12}$ De hecho, a algunos investigadores les llamaba la atención el bajo índice de indígenas 10 Dominique, Ibid, Estudios médicos realizados a esculturas de Occidente y a una pieza olmeca, evidenciaron la existencia de daños semejantes al que causa la leprosis, es decir, se representaron individuos con llagas, bubas, destrucción de boca, labios y ojos. En cuanto a la pieza olmeca, ésta asemeja el rostro leonino típico del leproso. Tales interpretaciones han propiciado varios diagnósticos como la tuberculosis, sífilis, tumores, micosis profunda o quizá simplemente la representación se deba al estilo artístico como en el caso de la cara olmeca. En cuanto a las piezas de Occidente es más probable que representen síntomas de sífilis o micosis, aunque éstas enfermedades se encuentran en polémica también.

11 Ana Paulina Malavassi Aguilar, "Los orígenes de la lepra en Costa Rica (1784-1821)”, en Mesoamerica Studies, Año 22, núm, 41, junio del 2001, Editores Armando J. Alfonso Urtrilla, Estados Unidos, p. 83.

$12 I b i d$, p. 78. Diversos estudios que se han realizado sobre el impacto de las enfermedades infectocontagiosas introducidas por los españoles en Centroamérica en la catástrofe demográfica sufrida por las 
contagiados, y no es que se deba a que hayan poseído cierta resistencia a la enfermedad, sino más bien el tipo de contacto que tuvieron con leprosos, Lester D. Mallory deduce que esto es debido al "factor Ratberg”. ${ }^{13}$

La atención para la lepra en la ciudad de México tuvo también connotaciones religiosas expresadas a través de la devoción católica a San Lázaro el Mendigo. En un principio, los esclavos negros y españoles fueron el factor de la diseminación de la lepra en la naciente Nueva España ${ }^{14}$ y aunque no había muchos enfermos, éstos deambulaban en la calle sin control, por tal motivo no dejaban de representar un riesgo de virulencia. Estos infectados no tenían un lugar en donde refugiarse, entonces Hernán Cortés, preocupado por tal situación, tuvo la iniciativa de ordenar la construcción (entre 1521 a 1524) de un sitio idóneo para los pacientes. ${ }^{15}$ Debemos reconocer que el conquistador no sólo fue el precursor en la atención de este mal, al ordenar construir una casa para leprosos, ${ }^{16}$ sino que también inició el culto a dicho santo, puesto que de la misma manera encargó edificar una ermita dedicada al abogado contra este mal.

La casa fue construida en un sitio denominado la Tlaxpana; ${ }^{17}$ pero como Cortés tenía fuertes rencillas y diferencias con Nuño de Guzmán, este último aprovechó que el Capitán General realizó un viaje a España en 1528, para mandar demoler las instalaciones por 1532. Para justificar la destrucción, Nuño de Guzmán argumentó que la casa para leprosos había sido construida muy cerca del principal abastecimiento de agua de la ciudad, por lo que se podría contaminar a los capitalinos mediante el vital líquido, por tal motivo este primer leprosario fue demolido y ni siquiera se reubicó, ni se volvió a construir otro refugio, en su lugar se levantaron suntuosas casas para Nuño de Guzmán. De inmediato el reclamo fue generalizado, siendo el

poblaciones autóctonas nunca hacen ninguna mención de la lepra (Se atribuye la debacle demográfica con mayor impacto a la viruela, el sarampión, el tabardillo etcétera.)

13 Lester D. Mallory, La lepra en el occidente de México, un ensayo etnohistórico, México, Publicaciones antropológicas de occidente, julio 1981, p. 44.

14 Conforme las relaciones comerciales iban aumentado con países cada vez más lejanos como China y las Filipinas, donde había muchos leprosos, el número de contagiados crecía.

15 José María Marroqui, La ciudad de México, v. III. México, Tip. y Lit. La Europea de J. Aguilar Vera y Cía. 1903, pp. 94-95.

16 México fue el punto de inicio para que refugios similares se construyeran en el resto del continente americano.

17 Hoy cerca de San Cosme, Distrito Federal. 
primer obispo y arzobispo de México fray Juan de Zumarraga quien encabezó las protestas. A pesar de que el rey ordenó la reconstrucción del leprosario, tal mandato no tuvo eco, ni fue acatado. Entonces los leprosos quedaron nuevamente desamparados, errabundos y mendigando en las calles alrededor de medio siglo, sin que nadie se ocupase de ellos.

Todo continuó así hasta que llegó un filántropo a la capital de la Nueva España que tuvo las fuerzas, la iniciativa y la visión para fundar instituciones inexistentes en estas tierras, obviamente los leprosos fueron su prioridad y aun sin apoyo, él mismo gestionó y se organizó para levantar un verdadero lazareto especializado. Este visionario fue el médico español llamado Pedro López, segundo con este nombre y profesión en la Nueva España. Tuvo grandes dificultades cuando reunió recursos financieros y para obtenerlos se valió de muchas formas, incluso pidiendo limosna. Se dice que al principio ni siquiera obtuvo la autorización del rey para fundar el nuevo hospital para leprosos, de igual manera fue calumniado, motivo por el cual le abrieron un proceso ante la inquisición en 1571, del cual fue absuelto. Finalmente obtuvo licencia el 23 de agosto de ese mismo año.

Le donaron gran parte del terreno donde Cortés había mandado construir las Atarazanas, que estaban ya en desuso y se encontraban en el oriente de la ciudad, ${ }^{18}$ ese sitio era idóneo porque poseía características propicias para fundar un leprosario pues estaba tan alejado de la capital que a nadie pareció importunarle, ya que se buscaba "evitar que el aire llevase los gérmenes nocivos a la ciudad”. ${ }^{19}$ En 1572 ya funcionaba el nuevo hospital de San Lázaro, bajo la administración de este mismo médico, quien sólo pidió que su patronato tuviera carácter hereditario. ${ }^{20}$ Entonces "se dio la orden de que ninguna persona enferma de lepra se curase en su casa, sino en el

18 En la época prehispánica los mexicas llevaban a cabo, en el mismo lugar, baños de tipo ceremonial, era conocido como Tetamazolco o lugar del sapo de piedra, mítico animal que se creía avizoraba las lluvias que mandaban Tláloc y sus Tlaloques a la tierra, al igual que la lepra según vimos anteriormente. En esos parajes, de igual manera se le rendía culto a otra deidad, la diosa Xilonen, vinculada al maíz tierno. Ésta era otra advocación de Atlantonan, divinidad igualmente asociada a las llagas expuestas, a las bubas y la lepra (¿̨). Quizá los españoles hallan tratado de implantar un templo católico en esa zona, para contrarrestar o suplantar allí la idolatría, esto se verifica en el plano atribuido a Cortés, pues en él se observa que al final de la calzada oriental de Tenochtitlan ya había sido erigido un "Templum ubi orant". desde tempranas fechas a la Conquista

19 Josefina Muriel, Hospitales de la Nueva España, México, v. 1, Ed. Jus, 1960, p. 49.

20 José Álvarez Amezquita, et al, Historia de la salubridad y de la asistencia en México, tomo III, México, Secretaría de Salubridad y Asistencia, 1960, p.169. 
hospital”. ${ }^{21}$ Los preceptos hospitalarios mantuvieron la línea filantrópica ya que se aceptaban todo tipo de clases sociales, sin distinción de fenotipos como mestizos, negros, indios, españoles y extranjeros. Estas características resultaron ser muy novedosas y adelantadas para su tiempo. En un mundo regido por la fe, como lo era el virreinal, los hospitales debían estar encaminados hacia principios religiosos, es por ello que estaban dedicados al patronato de Cristo, la Virgen o de algún santo especializado para contrarrestar el mal que se atendiera, en este caso fue San Lázaro., por esas razones era necesario contar con alguna capilla, templo o iglesia al interior o adjunta a los nosocomios. ${ }^{22}$

La vida religiosa fue imprescindible para que las instituciones marcharan adecuadamente, ya que la ciudadanía se organizaba en torno a ésta. En cuanto a los hospitales se fundaban cofradías o sociedades que ayudaban al sostenimiento de los mismos, además de que tenían responsabilidades encaminadas al cuidado de los enfermos y la contratación de doctores, boticarios y toda suerte de ayudantes como enterradores, barberos, cirujanos etcétera. Por ello el hospital de San Lázaro tuvo una capilla muy modesta, al principio, ideal como centro espiritual en donde los internos y la ciudadanía en general podían asistir, es por ello que fue construida extramuros. Indiscutiblemente en esos primeros altares estuvo San Lázaro, y el mismo Pedro López llevó una escultura de San Roque, santo llagado, abogado contra las pestes. Fue tal el éxito de esta devoción que se llegó a recaudar limosnas cuantiosas, ${ }^{23}$ por ello las monjas de San Juan de la Penitencia quisieron apropiarse de la imagen, por lo que se tuvieron que expedir autos para solucionar la querella, finalmente se dispuso que la imagen se quedara en San Lázaro.

El doctor Pedro López administró muy bien el lazareto y cuando murió en 1597 le sucedieron sus descendientes directos e indirectos como patronos. Es muy probable que existieran hermandades religiosas en el nosocomio desde muy tempranas fechas a su fundación, pero no tenemos datos exactos sino hasta el año de 1644, en que la cofradía de San Roque se encontraba organizando actividades relacionadas con fiestas taurinas. ${ }^{24}$ Pero el hospital tuvo su

$21 \quad$ Muriel, Ibid, p. 234.

22 En nuestros días reminiscencias de esta tradición las encontramos en los pequeños altares o capillitas que poseen diversos hospitales de la ciudad de México.

23 Dinero encaminado a la manutención de los leprosos y el hospital.

24 AGN. Reales Cédulas, grupo documental 100, v. 35. exp. 266, f. 236. 
más importante devoción con el traslado de la imagen de Nuestra Señora de la Bala a su capilla. ${ }^{25}$ En el momento de su llegada fue asumida como patrona del lazareto y su devoción derivó en beneficios para la institución, pues se organizó, aproximadamente en el año de 1660, una cofradía de españoles que ayudó al sostén de la institución y a la manutención de los leprosos pobres. Es verdad que las devociones a San Lázaro y a San Roque fueron precedentes a la causa de los leprosos, pero gracias al culto de la Virgen de la Bala se fundó la organización más importante que tuvo como principio los primeros tratamientos empíricos hacia la lepra y la atención a los pacientes, como más adelante veremos. La presencia y relación de esta imagen con el hospital de San Lázaro es indisoluble, puesto que de una u otra forma fue determinante en los altibajos del leprosario, así como lo fue para el amparo espiritual tanto de los internos como de la ciudadanía, además su devoción representó una poderosa entrada de fondos.

Precisamente es a través de las patentes de la Congregación y Hermandad de Nuestra Señora de la Bala, ${ }^{26}$ que sabemos algo sobre las actividades que esta sociedad realizaba al interior del hospital, al parecer algunos leprosos de igual manera pertenecieron a dicha hermandad. Aquel que deseara integrarse a esta cofradía, como primera medida, estaba obligado a pagar cuatro tomines de oro común, con el tiempo aportaría cada semana medio real y el 20 de diciembre de cada año daría cuatro tomines. Los miembros tenían como obligación contratar con sus propios fondos a un cirujano y a un médico reconocido de “ciencia y conciencia” para que atendieran y curaran a los leprosos pobres, asimismo los cofrades debían comprar las medicinas que necesitasen ellos y los pacientes. Aquellos que en cuatro meses no cumplieran cualquiera de sus compromisos, eran expulsados y borrados de las listas. Todos los miembros debían poseer

25 La virgen adquirió tan peculiar título porque ésta recibió un balazo que iba destinado a una mujer inocente. La tradición piadosa narra que sus dueños originales era un matrimonio que radicaba en el pueblo de Ixtapalapa. La relación entre ambos fue mermando a causa de la intromisión del demonio que acabó por persuadir al marido a través del infernal fuego de los celos y pensamientos de infidelidad que lo atormentaban, por lo mismo angustiaba a su señora mediante injurias y maltratos cotidianos, hasta que un día decidió matarla, cogió un arma y le disparó, en ese momento la inocente mujer se amparó con su amada esculturita de la Inmaculada Concepción y como escudo la imagen detuvo el artero balazo, de tal suerte que la bala quedó incrustada en la peana de la imagen. Dicho suceso fue asumido como milagro y así se le empezó a rendir culto a la imagen, misma que posteriormente fue sorteada entre las iglesias y templos de la ciudad de México, de esta rifa salió ganadora la capilla de san Lázaro. Con el tiempo se le adjudicaría el nombramiento honorífico de baluarte espiritual del oriente de la capital de la Nueva España. Al norte era la Virgen de Guadalupe, al poniente Nuestra Señora de los Remedios y la Piedad al sur.

26 AGN. Cofradías y Archicofradías. V. 195, exp. 14, exp. 9. 
la patente en forma impresa y firmada por el señor provisor y vicario general del arzobispado mexicano en turno. Cuando la extraviaban era obligatorio reponerla ante notario, ya que dicho documento era muy importante no tan sólo por ser su identificación oficial, sino porque daba mucho privilegio y prestigio ser miembro de una cofradía en el mundo virreinal. ${ }^{27}$

La congragación tenía especial interés en que los sepelios se llevasen adecuadamente y en perfecto orden, especialmente los de los cofrades. En el momento que un miembro moría todos debían dar diez pesos para cumplir con los derechos parroquiales; a los feligreses tenían que adquirirles un féretro para su sepelio, además era obligatorio contratar doce pobres a los que les tenían que comprar cirios y vestirlos con opas ceremoniales. ${ }^{28}$ Cada persona tenía una labor específica en las exequias, alguien llevaba y traía los ataúdes, otro cavaba la fosa, por último uno más acababa de introducir a la fosa y sepultar el ataúd, se ha dicho que estas medidas eran para evitar el contagio cuando se enterraba a un leproso. En los sepelios era imperioso que estuviesen presentes todos los demás oficiales y hermanos de la congregación, y cuando tuvieran una vicisitud y no pudieran asistir, debían justificar su falta. También tenían que mandar celebrar una misa rezada todos los sábados en la capilla del hospital, tanto para los hermanos vivos como para los muertos.

Era obligatorio que todos los miembros de la hermandad asistieran a la iglesia del leprosario el día 2 de febrero a las 9 de la mañana (ésta es la fecha más antigua de la que se tiene noticia se realizaba la festividad en honor a la Virgen de la Bala), pues ese día se debía reorganizar la dirección de la hermandad. Se elegía una nueva administración, mayordomos y diputados. También se debían celebrar ceremonias a Nuestra Señora de la Bala en todas las festividades restantes dedicadas a la Virgen María, especialmente la del 8 de septiembre por ser la fecha en la que se festeja el Nacimiento de la Santísima Virgen, también el 8 de diciembre (por la advocación a la que pertenece la Bala) y el 18 del mismo mes dedicado a la Expectación de Nuestra Señora. En todas estas citas se atendían a los leprosos y se les daba de comer a los

$27 \quad$ Por ejemplo, las patentes servían como cartas de crédito, con las que podían obtener préstamos y favores. De igual manera, quienes poseyeran la cédula de mayor antigüedad, ocupaban puestos claves en las mesas directivas de las hermandades.

28 Las opas eran una especie de túnicas rojas que generalmente usaban los niños del coro de la catedral metropolitana (información personal de la maestra Delia Pesat Arzave). 
que se encontraran en las enfermerías. ${ }^{29} \mathrm{~A}$ las $10 \mathrm{pm}$ de la Noche Buena, se realizaban una procesión dedicada a la milagrosa imagen, misma que se llevaba en andas, mientras se rezaba el rosario a coros. En ocasiones las procesiones eran acompañadas por nutridos séquitos de sacerdotes, mientras que clarineros, finas antorchas y linternas iluminaban y animaban la procesión. Se invitaba a los capitalinos novohispanos a estas procesiones mediante volantes impresos. ${ }^{30}$

Después de casi un siglo de actividades hospitalarias ininterrumpidas, a finales del siglo XVII y principios del XVIII, vino una disminución de las rentas que provocó el desinterés tanto de los descendientes de Pedro López como de la Hermandad de Nuestra Señora de la Bala hacia sus responsabilidades con el leprosario. Conflictos internos e incumplimientos de los lineamientos y la mala administración fue la característica de ese periodo. Así comenzó el deterioro de la institución en su aspecto arquitectónico y en la atención a los internos, probablemente la cofradía se desintegró por primera vez hacia la década de 1690.

Como la desorganización era más que evidente, no tardaron los reclamos y las llamadas de atención por parte del juez de Hospitales y Colegios de la ciudad, Juan Manuel de Olivan y Rebolledo, quien exigió que arreglaran el hospital o de lo contrario perderían el patronato, a menos que lo cedieran a quien tuviera el interés y el poder adquisitivo para solventar la remodelación. Los López decidieron ceder el patronato del hospital de San Lázaro a Buenaventura Medina y Picazo, biznieto de Pedro López, pero Juan Anguiano Picazo, patrón de San Lázaro en esos momentos había decidido ceder su administración a los hermanos de San Juan de Dios. Buenaventura Medina y Picazo optó por una resolución conciliatoria en la que aceptó reconstruir el leprosario con la condición de que "la renuncia de derechos hecha en su favor por sus sobrinos, había de

29 Nain Alejandro Ruiz Jaramillo, Nuestra Señora de la Bala, Baluarte espiritual del oriente de la ciudad de México, Tesis para obtener el título de licenciado en Historia por la UNAM, 2007, pp. 79-82.

30 AGN, Cofradías y Archicofradías. V. 195, exp. 14, exp. 9.77 fojas sin numerar donde existen patentes y documentos referentes a la Congregación y Hermandad de Nuestra Señora de la Bala. Hay información detallada: nombres de los miembros de dicha cofradía, actividades, informes del mayordomo, gastos y cuentas, un cuadernillo firmado por los sacerdotes que celebraron misas en honor a los hermanos difuntos y vivos, cantidad de dinero recibido en limosnas, salario de los boticarios, y doctores, etcétera. 
ser perpetua”, aunque fuera de manera honorífica. ${ }^{31}$ También los descendientes condicionaron su renuncia para que el hospital no fuera convertido en convento. Exigieron su derecho a sitios especiales durante las ceremonias religiosas en la iglesia, así como ser sepultados lo más cerca del altar mayor. Hubo beneplácito de la corona española en tales consideraciones, confirmando que seguiría siendo hospital y la institución pasó al cuidado de los juaninos. Los trabajos comenzaron por el año de 1720 y para la remodelación tanto del hospital como del santuario, el bachiller Buenaventura, en su labor de mecenas, gastó 110,244.00 pesos. Se contrató al célebre arquitecto Miguel Custodio Durán, quien inspirado en la arquitectura sevillana dejó su interesante impronta artística, advertida sobre todo en el templo del hospital, en la que tardó siete años en su construcción, y su espacioso camarín. Las fuentes dejaron constancia de que este templo fue uno de los más ricos en cuanto al ornato barroco novohispano de su tiempo.

Se realizaron mejorías en aspectos apremiantes, se introdujo agua potable con cañería propia y se retiró la acequia real aun más, ya que la humedad afectaba a los edificios. Buenaventura legó a los lazarinos una aportación para su vestido y sustento de pan con carne. También mandó agrandar aún más los salones y algunos, como si fuesen patios, incluían estanques individuales para que los leprosos tuvieran un espacio para bañarse, refrescarse y lavar su ropa. Se construyeron enfermerías dignas y a los frailes se les edificaron habitaciones tipo convento alto y bajo, también se cambiaron ventanas.

En el aspecto litúrgico y para armonizar las ceremonias religiosas, Buenaventura compró un órgano para el coro, una lámpara para el Santísimo Sacramento y unos vasos sagrados y ornamentos para la sacristía. En cuanto al culto a Nuestra Señora de la Bala, el bachiller refundó las capellanías en su honor y de San Lázaro. La imagen de la virgen fue colocada en el altar mayor, justo al centro de un bello retablo dorado, allí se encontraba resguardada en su nicho con cristales. ${ }^{32}$ De igual manera dispuso que las fiestas de la virgen fueran celebradas el 8 de cada mes. Para la decoración artística del camarín, que quedó a espaldas del altar mayor, contrató al

31 Manuel Orozco y Berra, "Ciudad de México”, en Noticias de la ciudad de México y de sus alrededores, México, Tipografía de F. Escalante, 1855, p.151.

32 Mariano Fernández de Echeverría y Veytia, Descripción histórica de las cuatro milagrosas imágenes de Nuestra Señora que se veneran en la muy noble, leal, e imperial ciudad de México, capital de la Nueva España, a los cuatro vientos principales, en sus extramuros y de sus magnificos santuarios, con otras particularidades, México, E. Aviña Levy, 1967, pp. 88, 89. 
famoso pintor barroco Nicolás Rodríguez Juárez, quien lo adornó con bellas pinturas dedicadas a esta advocación. Una de ellas incluía un trampantojo ya que se plasmó a un religioso de San Juan de Dios como si estuviese a punto de salir, quedó tan natural que engañaba al que de pronto entraba al camarín. ${ }^{33}$

El bachiller Buenaventura compró otras obras pictóricas, mismas que donó a la iglesia o al convento anexo. Actualmente sólo son conocidas dos de ellas; la más importante es una con el tema de los cinco Señores: Jesús, María, José, Joaquín, Ana, y a los lados se encuentran San Juan de Dios y San Lázaro el Mendigo. ${ }^{34}$ Esta obra se estaba arriba del altar de san Lázaro, y en el siglo XIX lo llevaron "a la sala chica del hospital” ${ }^{35}$ El otro es un San Gil Abad, cuya inscripción atestigua que fue un regalo del bachiller al lazareto ${ }^{36}$ En el presbiterio se pusieron dos lienzos, uno de san Juan de Dios y el otro del filántropo Pedro López en honor de su memoria.

Fueron realizadas otras pinturas, por ejemplo, en el altar mayor se llevó a cabo una en honor a la Virgen de Guadalupe, mientras que en un colateral se hizo otra más dedicada a Nuestra Señora de los Dolores. Buenaventura adquirió del Colegio jesuita las esculturas de San Pedro y San Pablo para colocarlas en el santuario, además se construyeron retablos donde fueron puestas las imágenes que la iglesia poseía desde su fundación y que eran asumidas como santos protectores del hospital. El actual cronista de la delegación Venustiano Carranza, José Estrella, encontró que la nueva cofradía de Nuestra Señora de la Bala en ese periodo mandó construir una especie de monumentos en honor a la Virgen para que los fieles se detuvieran a orar antes de llegar al santuario, es por ello que probablemente la moderna calle Manuel Negrete, llevó por muchos años el nombre de los Misterios. ${ }^{37}$ Las instalaciones quedaron en tan excelentes condiciones que el día 8 de mayo de 1728, en que fue dedicada la iglesia, se realizaron festividades por

$33 \quad$ Ibid.

34 Actualmente este lienzo se localiza en el Museo Regional de Querétaro y procede de las reservas de la antigua Academia de San Carlos.

35 Libro del inventario de la iglesia del hospital de san Lázaro, formado por el capellán Manuel Flores, del 23 de diciembre de 1840 al 31 de agosto de 1862, Archivo Histórico de la Secretaría de Salud, fondo Hospitales y Hospicios.

36 Gonzalo Obregón, La capilla de los Medina Picazo, México, INAH, 1971, pp-11-12. En 1971 se encontraba en la colección particular de la Sra. Angelina Grosso de Gómez.

37 José Estrella R. "El santuario de la Virgen de la Bala, en San Lázaro”, en Punto Medio, el informativo del Centro Histórico, México, 2002, pp-14-15. 
tan importante y generosa obra. La colaboración del bachiller no finalizó allí sino que siguió ayudando al leprosario con contribuciones pecuniarias hasta el día de su muerte, acaecida el 3 de septiembre de 1731. La nueva administración del leprosario no tardó en afrontar una de las mayores pruebas de su existencia ya que a finales del mes de agosto de 1736 dio inicio una espantosa epidemia que desoló a todo el virreinato y cobró la vida de miles de personas, en ese momento la ciudad de México fue la más castigada.

La ayuda de gente humilde de los alrededores de San Lázaro, animó al prior del hospital Fray José Peláez para que el nosocomio pudiera admitir a los contagiados más desfavorecidos. Impulsado por esta iniciativa y con la posterior ayuda de gente con más poder adquisitivo, el prior dio la orden de recibir a los infestados desde el 2 de enero del año de 1737. Entonces fueron internados 620 y, al igual que desde su fundación, no se discriminó a nadie para ser ingresado. A partir del día 11 de enero se comenzaron a enterrar los innumerables cadáveres en el camposanto del leprosario. Hubo 115 decesos en el hospital, pero 505 lograron aliviarse y la institución gastó 3,639 pesos por esta causa. Mientras tanto la gente recurría al amparo de sus devociones para contrarrestar lo que creían la ira divina, las crónicas refieren que:

No quedó imagen de alguna devoción en templos ni claustros, a quien no se votasen cultos particulares, y a quien no se invocase por tutelar y patrona en aquella aflicción. Aún se pensó traer a México a Nuestra Señora de Guadalupe, como se había hecho cuando la inundación de $1629 .{ }^{38}$

Fue entonces cuando la Virgen de la Bala adquirió notable peculiaridad en la vida religiosa de la ciudad. El presbítero Cayetano de Cabrera y Quintero subrayó la intercesión divina de la imagen en contra de la peste y la enfermedad:

Con que no hay duda queda que Ntra. Sra. De la Bala exaltada al Oriente de México ASCENDENTEM AB ORTU SOLIS, por un Ángel de paz, que contra la guerrera pestilencia, y qualquiera otra mortandad, levanta el Escudo de su Imagen. ${ }^{39}$

$38 \quad$ Cuevas, Ibid, p. 90.

39 Cayetano de Cabrera y Quintero, Escudo de armas de México, Introducción de Víctor M. Ruiz Naufal, México, 1981, IMSS, p. 155. 
Por este motivo, en el año de 1737 tuvo que fundarse nuevamente la cofradía de la Bala. Numerosos integrantes la conformaron esta vez y ese mismo año se autorizó dicha hermandad. Los cofrades realizaron emotivas peregrinaciones con la imagen a la cabeza, la popularidad a este culto se acrecentó y con ello las ganancias también “ya por el terror que la epidemia infundía, o bien porque el ruido de estas fiestas llamaron la atención del público hacia esa imagen, extendiendo la fama de sus milagros, ello fue que con esta ocasión aumentó el número de personas que se asentaron a su cofradía”. ${ }^{40}$ Otro culto afín y paralelo a Nuestra Señora de la Bala haría incrementar el fervor y la atención hacia la iglesia de san Lázaro. El hecho de que el Cristo del Balazo ${ }^{41}$ se cayera inexplicablemente de su lugar en una de las paredes de las escaleras fue retomado como una señal divina para que el culto a dicho crucifijo fuera impulsado. De esa manera y después de haber realizado algunos milagros, según reportaron los devotos de la época, fue mandado reparar y puesto en un altar digno.

La venta de novenas, escapularios y toda suerte de objetos votivos con el título de estas dos veneraciones era otra fuente de ingreso. Los dividendos que entraron de esta forma y en limosnas fueron imprescindibles para la manutención y el tratamiento de los pacientes del nosocomio. En ese periodo los hermanos de San Juan de Dios hicieron grandes esfuerzos y sacrificios para llevar a cabo sus múltiples actividades hospitalarias. La excelente administración que mantuvieron hizo que todo marchara ordenadamente en el hospital, toda vez que no tenían dinero para sustentar y curar a los enfermos, inclusive, hacia septiembre de 1776, todo el suelo era convertido en cama ante la falta de espacio, por tal motivo se pidió que se asignara algún financiamiento para el alimento de los internos así como para la ampliación de las enfermerías. ${ }^{42}$ Aun así se procuró atender a los pacientes, inclusive existen datos de que a principios de la década de 1780 se trataba de encontrar una cura para la lepra, en la que se experimentó nada menos que con lagartijas. ${ }^{43}$

No obstante la mala racha se acrecentaría en esa misma década, pues el dinero no fue suficiente, no se lograron reparar las urgencias más apremiantes y los juaninos (hartos e

$40 \quad$ José María Marroqui, Op. Cit. p. 101.

41 Llamado así porque en el año de 1692 recibió accidentalmente un balazo en uno de sus muslos.

42 Archivo Histórico del Distrito Federal, Ayuntamiento Vol. 2306, exp 1.

43 COL HN 21.1782, F. 237, del Archivo Histórico de la BNAH. En el Archivo Histórico del Distrito Federal, en el ramo de Ayuntamiento, se encuentran datos sobre tratamientos experimentales contra la lepra utilizando tarántulas, vol. 2307, exp 67, 1844. 2 fs. 
impotentes quizá) entraron en una etapa que se ha denominado como la "relajación de la orden", ya que sus responsabilidades hospitalarias y religiosas comenzaron a ser descuidadas, por lo mismo los reclamos de los leprosos se alzaron por la carencia de auxilio médico, y reclusiones forzadas.

Pero sin duda la escasez de comida era uno de los mayores problemas, esto puede ratificarse gracias a los análisis osteológicos llevados a cabo en osamentas de los lazarinos, que demostraron el bajo régimen nutricional. Al parecer la dieta de los leprosos estaba compuesta mayormente de un caldo preparado con retazos de cabezas y extremidades de venados. Otros animales como caballos y borregos eran parte de su alimentación, resultando mínimas las porciones de puercos y aves. ${ }^{44}$ Muchos comestibles eran donados, o comprados a través de los ingresos del hospital. En varios periodos fueron tan precarias las condiciones que a los hansenianos se les permitía ir a mendigar a la capital sin importar el riesgo de contagio a la ciudadanía. En tanto, los juaninos realizaban labores médicas fuera de la institución con la intención de conseguir más dinero. Varios leprosos optaron por huir aprovechando el nulo cuidado que existía. "Los religiosos entregados a otra clase de ocupaciones, parecían haberse olvidado de uno de los votos de su orden: el de la hospitalidad. Las quejas eran tan frecuentes que las autoridades se dieron por fin a la tarea de intervenir". ${ }^{45}$

El visitador Matías Gálvez mandó al rey una carta donde denunciaba estas anomalías y por eso fueron expulsados los hermanos en 1787. El hospital tuvo nombramiento de real al quedar bajo la administración del gobierno virreinal, pero en las postrimerías del siglo XVIII la situación otra vez decayó y los leprosos, sin control, huían de su aislamiento, ni rejas pudieron evitarlo. En el año de 1794 la administración y los enfermos del hospital de San Antonio Abad fueron integrados al de San Lázaro, por lo que la carga de trabajo se duplicó. Posteriormente un terremoto ${ }^{46}$ afectaría las instalaciones y a la iglesia, la cual quedó reducida a capilla, ya sin su espacio destinado a los leprosos quienes ahora asistían a misa junto con los sanos, motivo por el que muchos feligreses dejaron de asistir a este templo.

44 Luis Alberto López Wario, “El Hospital de San Lázaro”, en Investigaciones en Salvamento Arqueológico II, Departamento de Salvamento Arqueológico, Cuaderno 6, México, INAH, 1987, p. 78.

45 Francisco Santiago Cruz, Los Hospitales de México y la caridad de Don Benito, México, Ed. Jus, 1959, p. 62.

$46 \quad$ Irónicamente sucedió un día de San Juan de Dios del año de 1800. 
Hacia la primera década del siglo XIX el gobierno se declaró incompetente para sostener el leprosario por lo que se delegó la responsabilidad otra vez a la caridad religiosa, siendo el Arzobispo Lizana quien decidió regresar a los juaninos en 1815. El gobierno les cedió 10 años de goce de lotería y pensiones, pero aun así el dinero seguía escaseando y el agua también. En 1815 se asentaron las cosas que más urgían, tales como "colchones, sabanas, frazadas, colchas, almohadas, y se necesitaban calzones, calzado, y capotes para los pacientes masculinos. Para las mujeres, camisas, enaguas interiores y exteriores, rebozos, y calzado es decir con el atuendo con el que se les arropaba siempre". ${ }^{47}$

Ahora los juaninos resarcieron su relajación y atendieron de la mejor manera a los enfermos, procurando mantenerlos limpios y arropados. De igual manera se les conminaba al esparcimiento en el potrero y los patios del hospital. ${ }^{48}$ Con los levantamientos por la guerra de Independencia, los problemas se agudizaron al interior del lazareto, además en 1820 se ordenó la eliminación de las órdenes religiosas hospitalarias, esta medida obviamente repercutió en el desalojo definitivo de los juaninos y el nuevo gobierno independiente ni siquiera se acordó del hospital para leprosos.

El Ayuntamiento fue la institución que se ocupó de San Lázaro, pero fue en este periodo cuando se vivieron los peores sucesos de la historia del hospital pues los que se quedaron a cargo cometieron todo tipo de abusos; los diversos desordenes se vivían al interior hicieron que fuera necesaria una escolta. Al parecer no se encontraba humanidad ni en los capellanes de la iglesia, porque en ese periodo los leprosos se quejaron de éstos, ya que no cumplían con sus obligaciones espirituales. Uno en específico, llamado Manuel Ramírez de Revilla, se distinguió por sus fechorías, maltratos, ofensas y burlas a los leprosos. En palabras mismas de los internos, hasta su único consuelo les quiso robar porque "la Santísima Virgen de la Bala nos la ha quitado, para tenerla en su cuarto". ${ }^{49}$ Ramírez de Revilla fue denunciado por los leprosos ante el Ayuntamiento y se ordenó su destitución. En esta época los lazarinos siempre lamentaron la falta de carencia espiritual y médica:

$47 \quad$ AGN, Hospitales, v. 54. exp. 2. F. 115.

$48 \quad$ Al parecer esta vez hubo pocas quejas hacia ellos.

49 Archivo Histórico del Distrito Federal, Ayuntamiento, v. 2307, exp. 31. 
Conocemos que la enfermedad que tenemos no tiene remedio, que nos morimos, que nuestros parientes nos tienen asco, y miedo ¿pero es capaz que por esta razón ya no hemos de tener medicamento, para siquiera muramos? haciendonos algunas medicinas buenas que quizas haciendo diligencias p.vs no faltaría de algún médico que nos tuviera lastima y caridad siquiera cada tercer día para que a los P.P. no les cueste nada. ${ }^{50}$

En el panteón yacían cuerpos insepultos y tumbas profanadas, mientras tanto las fugas continuaban o los enfermos salían simplemente a embriagarse. Con el transcurrir de los años los problemas de una u otra forma se resolvían, resurgían o aparecían otros. Por si fuera poco, los parajes cercanos a San Lázaro fueron invadidos con basureros y cinturones de miseria, este fue realmente el inicio del colapso del hospital. La única luz en aquella penumbra vendría algunas décadas después con la labor humanitaria y de investigación de los doctores Ladislao Pascua, Rafael Lucio e Ignacio Alvarado. Cuando en 1843 fue nombrado director del Hospital el Dr. Lucio, el galeno Hilario Frías dejó un dramático testimonio de aquel dantesco ambiente que reinaba:

Yo que pasé algunos años de su clínica médica en aquel tristísimo hospital, practicando con el Dr. Lucio, no puedo recordar sin una onda melancolía, el aspecto horrible que presentaba el edificio, sobrio, viejo y con sus paredes negras, leprosas y desmoronándose, rasgadas por ondas grietas donde hormigueaban millares de lagartijas. Todo era alli tétrico y repugnante. Por horizontes los potreros mal cubiertos de un césped mezquino y amarillo, que luchaba con la sal de nitro que se extiende cual en las orillas del Mar Muerto, como una inmensa capa de espuma solidificada, que se hubiera desbordado del lago. Sobre aquel suelo convertido en el recipiente de todos los inmundos deshechos de la ciudad, se levanta el pesado paralelogramo del hospital, con su vieja iglesia precedida del cementerio donde se sepultaban los cadáveres de los lazarinos, y con sus salones de un solo piso, donde estaban las enfermerías. Sobre aquella cárcel de leprosos, sobre aquel conjunto de charcos de agua sucia y espesa 
que lenta y penosamente despiden los atajos, reverbera un solo de fuego que vivifica millones de inmundos insectos que hierven en el suelo o nublan el viento. Sólo los que pasamos alli las primeras horas de la mañana, curando centenares de ulceras una a una, y haciendo las guardias nocturnas encerrados en aquella mazmorra más terrible y repugnante que los presidios de la costa, pudimos estimar la importancia de los trabajos del Dr. Lucio, que ayudado por una administración filantrópica pudo ir mejorando la situación de los asilados. ${ }^{51}$

El resultado de aquellas prácticas de la ciencia médica fue la obra Opúsculo sobre el mal de San Lázaro, o elefanciasis de los griegos que llevaron a cabo los doctores Ignacio Alvarado y Rafael Lucio, este último galeno, en el año de 1851, llevó la investigación sobre las formas en que se manifiesta la lepra ante la Academia. Es digno de mencionarse que precisamente, a partir de tales labores de los doctores en el hospital, aquellos que padecieron la lepra por vez primera fueron tratados bajo medidas científicas, ya que antes del arribo de dichos médicos el tratamiento estaba basado principalmente en el empirismo y los prejuicios religiosos, puesto que se atribuía el contagio de la enfermedad a la brujería y a la carne de cerdo, en especial al tocino que habían consumido los pacientes.

Recordó con sarcasmo el doctor Rafael Lucio: “Los desagradables lazarinos eran tratados como leprosos de Palestina [...] y se aplicaba a los que sufrían, muchos de los preceptos del libro de Moisés”. ${ }^{52}$ Se descubrió un padecimiento particular de tal enfermedad a la que el doctor Lucio denominó como "manchada y que no se encuentra descrita en ninguna obra publicada hasta hoy, que yo conozca [...] lo que hace creer que dicha enfermedad sea propia de México y enteramente desconocida de los autores europeos”, ${ }^{3}$ esto le valió que a manera de reconocimiento tal padecimiento recibiera el nombre de "Lepromatosis Difusa de Lucio”. Las aportaciones de estos galenos siguen siendo de interés e importantes para la historia de la ciencia médica.

$51 \quad$ Luis González Obregón, México Viejo, Edición facsimilar de 1900, México, Porrúa, 1976, pp. 127-128

52 Ignacio Alvarado y Rafael Lucio, Opúsculo sobre el mal de San Lázaro, o elefanciasis de los griegos, escrito por los profesores Rafael Lucio e Ignacio Alvarado, México, Secretaría de Fomento, 1889, 31 p.

53 Francisco Sosa, Las estatuas de la Reforma, Biblioteca del Estudiante Universitario, México, UNAM, No 119, 1996, p. 23. 
La ley de 1857 afectó al lazareto y con el decreto del 2 de febrero de 1861 fue suprimido y cerrado de forma definitiva en 1862. La finca que poseía el hospital fue valuada en 11,600 pesos y paulatinamente los terrenos que comprendían el hospital fueron vendidos y fraccionados para edificar fábricas, casas habitacionales y rastros, etcétera. Fue demolido casi todo a excepción de la iglesia que se suponía iba a quedar abierta al culto, pero no fue así y sus bienes fueron dispersos. ${ }^{54}$

Primero se pensó trasladar a los leprosos al convento de Churubusco pero al final se les trasladó al convento de San Pablo, que después sería conocido como Hospital Juárez I, y en 1915 los llevaron al Hospital General, en donde ni doctores de planta tuvieron durante mucho tiempo. La suerte de los leprosos siguió en el infortunio porque se les continuó atendiendo de la peor forma en estos asilos. Luego se dispuso separar los sexos, los hombres fueron llevados al arruinado lazareto militar de Tlalpan y las mujeres, que corrieron con mejor suerte, fueron asiladas en la casa "Hogar Esperanza”. También se fundó el moderno leprosario llamado justamente “Dr. Pedro López”, que se encuentra en el km 34.5 de la carretera federal MéxicoPuebla, Ixtapaluca, en lo que había sido la Hacienda de Zoquipan, allí se internaron a los hansenianos el 11 de diciembre de $1939 .{ }^{55}$

\section{La paz llega a los leprosos en el siglo XX}

La concienciación sobre lo que esta enfermedad representaba no sólo en la ciudad de México sino que a nivel nacional, se debe gracias a la obra del doctor Jesús González Ureña quien lo advirtió en su Manera de iniciar en México la profilaxis antileprosa, allí resaltó las medidas más apremiantes, mismas que poco a poco se fueron llevando a cabo, la mayoría bajo su propio esfuerzo. Una de sus iniciativas fue la creación de estadísticas oficiales sobre el registro de los lazarinos a partir de 1921, también impulsó el primer censo en 1925, el cual reveló que en

$54 \quad$ Igual suerte corrieron las históricas imágenes de los santos patronos y no se sabe su paradero de la mayoría. La Virgen de la Bala fue trasladada al hospital de Jesús Nazareno, allí fue robada y tiempo, después fue descubierta en el empeño, la rescató el presbítero Rosendo Pérez Ynisestra, quien la regresó al pueblo de Ixtapalapa, allí la imagen vivió todo tipo de suertes hasta perderse en la memoria colectiva. Durante mucho tiempo se creyó desaparecida pero gracias a mi trabajo de investigación de tesis reporté el "hallazgo", ya que su culto fue resguardado celosamente por los nativos del pueblo.

55 Obdulia Rodríguez, "La lucha contra la lepra en México", en Revista de la Facultad de Medicina, UNAM, volumen 46, número 3, mayo-junio, p. 109-113. Actualmente sigue funcionando dicho hospital. 
ese momento existían 1,450 casos en todo el país. ${ }^{56}$ Durante los primeros años de la década de 1930 se promulgó el reglamento Federal de Profilaxis de la Lepra,y fue actualizado en 1956.

A Jesús González Ureña se le debe la creación de 21 dispensarios en las zonas con mayor índice de enfermos, además de las juntas Centrales Municipales de Profilaxis de la Lepra y un sanatorio con capacidad para 500 enfermos de lepra, y el ya mencionado "Pedro López”. Algunos dispensarios se convirtieron en verdaderos Centros Dermatológicos. ${ }^{57}$ Otra persona que amerita reconocimiento es el doctor Fernando Latapí (1902-1989), que entre otras cosas complementó el trabajo y los descubrimientos del doctor Lucio sobre la lepra "difusa” o eritema necrotizante. ${ }^{58}$ En 1948 fundó con algunos de sus colaboradores la Asociación Mexicana de Acción contra la Lepra, A.C. e impulsó campañas para atender a los lazarinos en sus comunidades, de esta forma se descubrieron 7 mil nuevos casos. Siempre tuvo el tino de preparar a las nuevas generaciones de enfermeros, médicos y epidemiólogos sobre lo que la lepra representaba.

Podemos decir que a partir del 15 de marzo de 1941, en que Guy H. Famet y Col comenzó a utilizar el promín contra la lepra, tal medida habría de cambiar radicalmente el tratamiento a dicha endemia por primera vez en la historia de la humanidad. Así comenzó la tranquilidad para los leprosos después de siglos de sufrir discriminaciones, ostracismo y reclusiones forzosas. El tratamiento para la cura de tan terrible enfermedad mejoró con la administración de la dapsona, que al principio tuvo efectos secundarios pero el método mejoró a partir de la década de 1980. La combinación de antibióticos condujo finalmente a un tratamiento altamente eficaz y con posibilidad de curación real de los pacientes. ${ }^{59} \mathrm{En}$ México, desde principios de la década de 1990 se usa una combinación de tres fármacos: dapsona, clofazimina y rifampicina. El tratamiento actual consiste en dosis diarias y mensuales autoadministradas, las cuales deben ser supervisadas por leprólogos. La combinación de

$56 \quad$ Lester D. Mallory afirmó que este censó no registró al doble de esa cifra, Ibid, p 20.

57 Rodríguez, Ibid, p. 110.

58 Por ello el padecimiento lleva su nombre junto al del doctor Lucio "Lepramatosis difusa de Lucio y Latapí”.

59 Rodríguez, Ibid. 
los fármacos es conocida como Poliquimioterapia (PQT). El índice de la lepra en México efectivamente ha disminuido y se está llegando a la meta de un paciente por diez mil sanos. ${ }^{60}$ Esto tampoco significa que el éxito sea total pues todavía hay demasiada desinformación sobre dicho padecimiento, y no sabemos sí las posibilidades de mutaciones de la patología o resistencia a los fármacos deriven en la persistencia del mal bajo otras formas.

\section{Conclusiones}

Como pudimos advertir desde el siglo XVI hasta muy avanzado el XX la lucha contra la lepra en México fue obra exclusivamente de personas aisladas con filiaciones filantrópicas y con un profundo espíritu cristiano encaminado hacia la ayuda de los enfermos, otras personas, como el caso de Cortés, fueron simplemente visionarias. Sin olvidar al mismo Pedro López y sus descendientes, destacando su biznieto Buenaventura de Medina, sin olvidar múltiples sacerdotes y frailes hospitalarios como los juaninos que actuaron de buena fe y con la intención de ayudar al prójimo. Los hermanos de San Juan de Dios al igual que sus predecesores del siglo XVI fueron religiosos que vinieron a América como dice Semo: “no para lucrar, si no para realizar los ideales de una iglesia en pleno de transformación, marcada por la aspiración de un regreso a los ideales de un cristianismo primitivo. Entre estos hombres se encontraron todos los talentos necesarios."61

El culto a las imágenes hospitalarias en países de tradición católica como México fueron importantes antecedentes para el desarrollo y aplicación del tratamiento médico, tanto en la época novohispana como en la posterior evolución científica, es por esto que el caso del nosocomio de San Lázaro es singular, pues finalmente la responsabilidad quedó en manos de los doctores profesionales eminentes como Ladislao Pascua, Hilario Frías, Rafael Lucio e Ignacio Alvarado, quienes dieron los primeros pasos hacia el adecuada atención médica. En el siglo XX los doctores Jesús González Ureña y Fernando Latapí lograron que la enfermedad fuera asumida como un problema de salud pública y una responsabilidad del gobierno. Gracias

60 Elizabeth Ferreira, Mario Martínez, La eliminación de la lepra en México, México, Sistema Nacional de Vigilancia Epidemiológica, Epidemiología, Sistema Único de Información, Número 4, Volumen 19, Semana 4, Del 20 al 26 de enero del 2002.

61 Apud, López Wario, p. 81. 
a todos ellos ahora ya no se delega dicho compromiso simplemente a la caridad religiosa o a devociones populares como en otros tiempos.

Las veneraciones hacia Nuestra Señora de la Bala y San Lázaro sobreviven hasta nuestros días, sin embargo, llama la atención que el culto a la virgen francamente haya sustituido al de San Lázaro, ello quizá se deba a que el culto a dicho santo llagado era demasiado especializado y la lepra no era la prioridad entre los capitalinos como en cambio sí lo eran otras vicisitudes de la vida cotidiana, recordemos que la Virgen de la Bala tenía la singularidad de aliviar enfermedades así como los problemas conyugales.

Otra causa sería que la misma Iglesia aceptó la inexistencia de dicho santo, el cual ha sido confundido con San Lázaro, obispo de Betania, aquel a quien Jesús resucitó. ${ }^{62} \mathrm{La}$ tradición de San Lázaro Llagado deriva del imaginario popular católico y creado a partir de una mala lectura de los evangelios de San Lucas (versículos del 26 al 19), en donde Cristo narra la parábola de un hombre desposeído llamado Lázaro, al que describió llagado y que se encontraba tendido en las puertas de la casa de un rico anónimo. Se narra que Lázaro sólo deseaba saciarse con las sobras que caían de la mesa del hombre acaudalado pero solamente logró que los perros le lamieran las llagas. Cuando murieron los hombres el mendigo fue al cielo y el rico al infierno. En realidad en esta parábola creada por Jesús deseaba manifestar su ideal de justicia mediante su particular visión dialéctica entre ricos y pobres.

Sin importar lo anterior fue creado todo un culto e iconografía en honor al Llagado, es más, se aseguraba que Cristo había sido su biógrafo o historiador. Por tal motivo el santo es representado según la descripción de Jesucristo, es decir, un anciano semidesnudo y sin calzado. En las representaciones porta una pequeña túnica púrpura que apenas cubre su cuerpo, también usa muletas pues como Jesús mencionó que estaba tendido, se pensó que tenía problemas de tullimiento o que era minusválido. Lo acompañan dos perros (uno de color café y el otro blanco, en ocasiones con manchas café) que lamen sus llagas. Al fondo,

62 De hecho, ambos santos son festejados el 17 de diciembre. 
sin excepción, se destaca un castillo majestuoso donde se supone que vive el hombre rico.

Desde la antigüedad se ha creído en la existencia de este Lázaro, quien desde entonces ha sido conocido como abogado en contra de las enfermedades contagiosas, en especial la lepra. Del mismo modo ha sido llamado gloriosísimo patrón y protector de los pobres. Resulta asombroso que actualmente, en varios altares de los templos e iglesias católicas, hay imágenes de este santo. Todavía es posible comprar la "Novena en Honor a san Lázaro, abogado especial contra las enfermedades contagiosas”, en la página 9 se lee: "Pues que Cristo expresamente quiso ser tu historiador sé Lázaro protector de que a ti clame indulgente”. Hay datos que corroboran que el culto a San Lázaro en el leprosario de la ciudad de México era criticado y señalado como erróneo, pues en 1822 el párroco de la Soledad y Santa Teresa se negó rotundamente para que se pidiera limosna en nombre de la imagen de San Lázaro el leproso, ante tal suceso un feligrés dejó constancia de tal negativa, por medio de un reclamo:

Porque la Iglesia no lo tenía recibido por santo [...] y que sólo permitiría la de san Lázaro Obispo para la colocación de la limosna en su curato [...] venero los ilustrados conocimientos del Sr. Cura, pero esta ocurrencia es tan rara [...] fue objeto parece escandaloso porque destruye una tradición o creencia que me parece autorizada por la Iglesia y [...] V. M. juzgase conveniente aclarar el caso, podrá disponer se pase a este expediente al sr. Provisor, pidiendo un juicio y lo demás que estime necesario. ${ }^{63}$

Irónicamente en el templo de la Soledad hoy existe una imagen de San Lázaro Llagado. No obstante, sin importar prejuicios religiosos ortodoxos o de otra índole, debemos reconocer que a lo largo de la historia y gracias a esta inocente devoción se construyeron varios leprosarios en honor a tal advocación, donde se internaron a quienes sufrían del padecimiento que ha sido denominado por siglos como “el mal de San Lázaro”. Tampoco olvidemos que para atender a la gente recluida en dichos nosocomios de igual forma se organizaron y fundaron varias órdenes religiosas lazarinas. ${ }^{64}$ Alrededor del año 1120 fue fundada en Jerusalén una orden de frailes hospitalarios que tenían la responsabilidad tanto de proteger a los cristianos de oriente

$63 \quad$ Archivo de la Ciudad de México, Ayuntamiento, v. 2306, exp. 28.

64 Ruiz Jaramillo, Ibid, pp 239-231. 
como a los leprosos. En los reinados de Luis VII y Luis IX la iniciativa fue llevada a Francia y expandida (1140-1250). "Posteriormente fue convertida en orden de caballerías y absorbidas por otras órdenes, siendo actualmente sus últimos miembros acogidos en Italia en la orden de San Mauricio”. ${ }^{65}$ Hoy este culto ha sido asimilado por el esoterismo popular que le rinde una veneración acendrada. En el mercado de Sonora, de la delegación Venustiano Carranza en la ciudad de México, existe una capilla especial dedicada a este santo con fines espiritistas. Asimismo debe mencionarse la estima y devoción que se tiene por San Lázaro el Mendigo en Cuba, venerado justamente en el leprosario del Rincón, a donde cada 17 de diciembre, día de su festividad, acuden innumerables fieles a mostrar su fervor. ${ }^{66}$

La religión católica no habría de quedarse sin un leproso en sus altares pues el padre Damián de Molokai (1840-1889), de origen belga, fue beatificado por Juan Pablo II en 1994. Tal clérigo ha sido denominado como “El leproso voluntario” o el “Apóstol de los leprosos”, y patrono de los que trabajan entre estos enfermos. Su vida la dedicó a la ayuda de los lazarinos que habían sido desterrados a la isla-leprosario de Molokai en Hawai. En dicho sitio abandonaban a su suerte a los hansenianos, sin ninguna ayuda humanitaria o social. Con tal de poder atender y ayudar a los enfermos aceptó vivir en las mismas condiciones de éstos, sabiendo que resultaría contagiado. Este ejemplo manifiesta que ese mismo espíritu religioso y de compasión filantrópica hacia los leprosos puede canalizarse en la adecuada atención de los más olvidados y despreciados, como lo han sido los leprosos.

\begin{abstract}
ARCHIVOS
Archivo General de la Nación (AGN)

Ramos: Cofradías y Archicofradías, General de Parte, Hospitales, Reales Cédulas, y Cabildos.

Archivo Histórico del Distrito Federal. Fondo: Ayuntamiento.

66 Ruiz Jaramillo, Ibid, pp 239-240. Lázaro el mendigo, en aquél país caribeño es asumido como la identificación del poderoso orisha Babayú-Aye de la religión santera yoruba, igual suerte ha corrido la Virgen María, en su advocación de las Mercedes, la de Regla, o la Caridad, también santa Bárbara y san Martín caballero, que han sido muy bien recibidos por los espiritistas de aquel país caribeño.
\end{abstract}

65 López Wario, Ibid, p. 80. 
Archivo Histórico de la Secretaría de Salud.

Fondo: Hospitales y Hospicios.

Archivo Histórico de la Biblioteca Nacional de Antropología e Historia.

Colección Hospital de Naturales.

\section{BIBLIOGRAFÍA}

Álvarez Amezquita, José, et al, Historia de la salubridad y de la asistencia en México, tomo III, México, Secretaría de Salubridad y Asistencia, 1960, p. 891.

Alvarado, Ignacio, Rafael Lucio, Opúsculo sobre el mal de san Lázaro, o elefanciasis de los griegos, escrito por los profesores Rafael Lucio e Ignacio Alvarado, México, Secretaría de Fomento, 1889, p. 31.

Broda, Johana, "Las fiestas aztecas de los dioses de la lluvia: una reconstrucción según las fuentes del siglo XVI”, en Revista de Antropología Española Americana, Madrid, Vol. 6, [s.n.], 1971, pp. 255. 256.

Cabrera y Quintero, Cayetano de, Escudo de armas de México, Introducción de Víctor M. Ruiz Naufal, México, 1981, IMSS, p. 552.

Cuevas S. J., Mariano, Historia de la iglesia en México, t. 1, México, Imprenta del Asilo, 1921, p. 493.

D. Verut. M. D., Dominique, Precolombina dermatology \& Cosmetology in Mexico, Italia, Amilcare Pizzi, 1973, sn.

Estrella R., José “El santuario de la Virgen de la Bala, en san Lázaro”, en Punto Medio, el informativo del Centro Histórico, México, 2002, pp-14-15. 
Fernández de Echeverría y Veytia, Mariano, Descripción histórica de las cuatro milagrosas imágenes de Nuestra Señora que se veneran en la muy noble, leal, e imperial ciudad de México, capital de la Nueva España, a los cuatro vientos principales, en sus extramuros y de sus magníficos santuarios, con otras particularidades, México, E. Aviña Levy, 1967, p. 89.

Ferreira, Elizabeth, Mario Martínez, La eliminación de la lepra en México, México, Sistema Nacional de Vigilancia Epidemiológica, Epidemiología, Sistema Único de Información, Número 4, Volumen 19, Semana 4, Del 20 al 26 de enero del 2002, p. 3.

González Obregón, Luis, México Viejo, Edición facsimilar de 1900, México, Porrúa, 1976, p. 739.

Gonzalo Obregón, La capilla de los Medina Picazo, México, INAH, 1971, p. 79.

Hayden, Doris, “El cuerpo del dios: el maíz”, en Animales y plantas en Mesoamérica, Yólotl González Torres (coord.), CONACULTA, INAH, México, Sociedad Mexicana para el Estudio de las Religiones, 2001, pp. 19-37.

López Wario, Luis Alberto, “El Hospital de San Lázaro”, en Investigaciones en Salvamento Arqueológico II, Departamento de Salvamento Arqueológico, Cuaderno 6, México, INAH, 1987, p. 78.

Malavassi Aguilar, Ana Paulina, “Los orígenes de la lepra en Costa Rica (1784-1821)”, en Mesoamerica Studies, Año 22, núm, 41, junio del 2001, Editores Armando J. Alfonso Urtrilla, Estados Unidos, pp. 77-97.

Mallory, Lester D., La lepra en el occidente de México, un ensayo etnohistórico, México, Publicaciones antropológicas de occidente, julio 1981, pp. 37-45.

Marroqui, José María, La ciudad de México, v. III. México, Tip. y Lit. La Europea de J. Aguilar Vera y Cía. 1903, p. 754. 
Muriel, Josefina, Hospitales de la Nueva España, v. 2, México, Ed. Jus, 1960.

Orozco y Berra, Manuel, “Ciudad de México”, en Noticias de la ciudad de México y de sus alrededores, México, Tipografía de F. Escalante, 1855, p.151.

Rodríguez, Obdulia, “La lucha contra la lepra en México”, en Revista de la Facultad de Medicina, UNAM, vol. 46, núm. 3, mayo-junio, pp. 109-113.

Sahagún, Fray Bernardino de, Historia General de las cosas de Nueva España, anotaciones y apéndices de Ángel María Garibay K., México, Porrúa, 1997, p. 1093.

Spigelman, A. Rafl, M. et al, "DNA of Mycobacterium leprae Detected by PCR in Ancient Bone" en International Journal or osteoarchaelogy, Estados Unidos, North American Editor, Associate Editors, 1994, pp. 288-290.

Ruiz Jaramillo, Nain Alejandro, Nuestra Señora de la Bala, Baluarte espiritual del oriente de la ciudad de México, Tesis para obtener el título de licenciado en Historia por la UNAM, 2007, p. 295.

Santiago Cruz, Francisco, Los Hospitales de México y la caridad de Don Benito, México, Ed. Jus, 1959, p. 62.

Sosa, Francisco, Las estatuas de la Reforma, Biblioteca del Estudiante Universitario, México, UNAM, 119, 1996, p. 23.

Terencio de las Aguas, José, Consideraciones histórico-epidemiológicas de la lepra en América, Med Cutan Iber Lat Am, 2006, 34, 179-194. 